* Profa. Dra. pesquisadora do Laboratório de Ensino Pesquisa e Extensão da Universidade Estadual de Londrina

** Graduanda em Direito pela Universidade Estadual de Londrina

*** Graduanda em Direito pela Universidade Estadual de Londrina

\section{Os Efeitos Da Decadência Da Esfera Pública}

\author{
Effects Of The Decay Of The Public Sphere
}

\section{Luci Ribeiro* \\ Hellen Luana de Souza** Daniela Lucca Rocha***}

Como citar: RIBEIRO, Luci, SOUZA, Hellen Luana de. ROCHA, Daniela Lucca. Os efeitos da decadência na esfera pública. Revista do Instituto de Direito Constitucional e Cidadania, Londrina, v. 3, n. 1, p. 155-170, jan/jun. 2018. https://doi.org/10.48159/revistadoidcc.v3n1.ribeiro.souza.rocha

Resumo: Partimos da hipótese de que oisolamento da esfera pública é responsável por reforçar os laços da comunidade ao permitir a criação de uma identidade comum e restrita em detrimento da busca por consolidação de interesses gerais. Logo, a concretização da Democracia é impossibilitada, já que para a sua ocorrência é necessário que haja um contato entre os diversos atores sociais. Avalorização social do pequeno grupo atomizado limita o exercício da Cidadania e a consumação dos Direitos Fundamentais, bases essenciais do Estado Democrático de Direito. Tais direitos, assim como a Cidadania, necessitam de um esforço conjunto de pessoas conscientes de seu pertencimento a uma sociedade, capazes de agir em busca do bem-comum e da justiça. Esse paper propõe uma problematização dessa temática através de umdebate bibliográfico com aplicação do método dedutivo, tomando como base - principalmente - as obras de Hannah Arendt, Richard Sennett e Norberto Bobbio, e tem por objetivo descortinar os impactos do esvaziamento da esfera pública no regime democrático sobre os direitos fundamentais.

Palavras-chave: Esvaziamento da esfera pública. Direitos Fundamentais. Democracia. Cidadania.

Abstract: We start from the hypothesis thatthe public sphere isolation is responsible for strengthening the bonds of the community to allowing the creation of a common and restricted identity in detriment of the search for general common interests. Therefore, the concretization of Democracy is impossible, since for its occurrence is necessary that there is an intersubjective contact between the different social actors. When valuing the small atomized group, the exercise of Citizenship and the consummation of Fundamental Rights, essential characteristic of the Democratic State of Right, is limited. This rights, as well as Citizenship, require a collective effort of people aware of their 
belonging to society, be capable to acting in search of the common good and justice. This study discussed deals with the topic through a bibliographical debate with application of the deductive method, based mainly on the works of Hannah Arendt, Richard Sennett and Norberto Bobbio, and aims to uncovering the impacts of the emptying of the public sphere in the regime fundamental rights.

Keywords: Emptying of the public sphere. Fundamental rights. Democracy. Citizenship. 


\section{INTRODUÇÃO}

Este artigo abordará o esvaziamento da esfera pública na contemporaneidade. Essa problematização deve-se à percepção de que a participação na esfera pública adquire progressivamente o caráter de mera obrigação formal em função da supervalorização da comunidade causada pelo retraimento para uma esfera particular. Conduzindo, dessa forma, à limitação da interação intersubjetiva que dificultaa concretização do regime democrático. Esse argumento pode encontrar respaldo empírico na pesquisa realizada pelo Instituto Data Folha, segundo a qual em 2017 , em relação a 2016 , houve um recuo de $62 \%$ para $56 \%$ ao apoio à democracia ${ }^{1}$. Certamente um reflexo da crise política, resultante, principalmente, da falta de participação política.

O desinteresse dos indivíduos pelo corpo social e a consequente não participação na vida política abre o espaço para uma ação política descaracterizada da busca pelo bem comum. Alguns líderes políticos passam a ser divinizados por se expressarem de uma forma que o restante da sociedade não é capaz. Como resultado disso, tem-se a personalização da política, esta é reforçada pelos artifícios de marketing das propagandas eleitorais. Atrelado a essa personalização e ao seu efeito antidemocrático está o enfraquecimento da supressão da cidadania que, por não ser exercitada e valorizada, perde - na visão dos indivíduos - o seu significado.Ao passo que o isolamento em comunidade atinge um nível tão extremo que seus membros deixam de compreender a complexidade do todo, a relação necessária entre as macro e as micro relações sociais; dificultando, desse modo, a concretização da democracia e dos direitos fundamentais.

Diante do exposto verifica-se na literatura jurídica, sociológica e da ciência política, autores e abordagens que auxiliam a compreensão dessa problemática, bem como apresentam possíveis alternativas de superação. Dentre esses autores destacamos Hannah Arendt, Richard Sennett, Norberto Bobbio e Paulo Bonavides dos quais algumas obras foram utilizadas no debate bibliográfico e atividade dedutiva realizada no presente artigo.

\section{O ESVAZIAMENTO DA ESFERA PÚBLICA}

A abordagem do fenômeno do esvaziamento da esfera pública, problema que assola a modernidade, feita por Richard Sennett e Hannah Arendt, mostra como causas que convergiram para o abandono do domínio público a união do secularismo ao capitalismo industrial. Segundo Sennett (SENNETT, 2014) $)^{2}$, esse fato proporcionou o desenvolvimento de uma sociedade intimista impulsionada na proporção em que o domínio público é abandonado, sendo que um decorre necessariamente do outro.

O domínio público, por sua vez, é compreendido por Hannah Arendt (ARENDT, 2007) ${ }^{3}$ como um espaço comum, onde o indivíduo interage com os demais na esperança de ser

1 APOIO À DEMOCRACIA RECUA. INSTITUTO DE PESQUISAS DATAFOLHA. Disponível em: < http:// datafolha.folha.uol.com.br/opiniaopublica/2017/10/1923930-apoio-a-democracia-recua.shtml $>$ Acesso em: 09. Out .2017

2 SENNETT, Richard.O declínio do homem público: as tiranias da intimidade. Tradução de Lygia Araujo Watanade. Rio de Janeiro: Record, 2014, p. 28. Tradução de The fall of public man.

3 ARENDT, Hannah. A condição humana. Tradução de Roberto Raposo. 10. ed. Rio de Janeiro: Forense Universitária, 2007, p. 59. Tradução de The Human Condition. 
ouvido e compreendido, exigindo assim a ação dos homens em meio a pluralidade. Nisso reside o grande problema da modernidade, pois os indivíduos não são capazes de representar em público e entrar em contato com o desconhecido, são para Sennett "atores sem uma arte" (SENNETT, 2014, p. 450$)^{4}$, desprovidos da arte de expressar-se em um ambiente plural.

Como foi dito anteriormente, o secularismo na modernidade pode ser considerado uma das causas desse esvaziamento; na medida em que foi se expandindo,retirou dos homens a capacidade de interagir com o estranho, com o desconhecido. Assim, gradativamente, o espaço público sempre repleto de estranhos passou a ser temido, pois a interação social assemelha-se a um ritual. Em virtude disso aquela capacidade ora exercitada numa sociedade não-secular passou a inatividade, fazendo com que o estranho fosse interpretado de forma diversa, não mais como a possiblidade de entrar em contato com o novo, mas como algo ameaçador a ser evitado. Subvertendo assim, o que Sennett (2014) ${ }^{5}$ considerava próprio de uma sociedade não secular, na qual os componentes do espaço público eram vistos como pertencentes a ordem da natureza, possuíam um lugar e eram, por isso, possíveis de serem compreendidos, ao contrário de uma sociedade secular, marcada pela preferência por coisas e sensações imediatas deslocadas no espaço não precisando ser interpretadas dentro do todo.

Ao processo de secularização soma-se o desenvolvimento do capitalismo industrial, este último compreende tanto as relações de trabalho quanto as relações de comércio. O trabalhador foi dissociado de seu trabalho, ficando restrito a operar uma única etapa e alheio ao processo de produção bem como as pessoas que executavam as outras etapas ${ }^{6}$. À medida que se transpôs essa dissociação para a sociedade o todo passou a não ser compreendido em sua devida importância, porque as partes não se viam inclusas no corpo social. Além disso, como descreve Sennett (2014) ${ }^{7}$, os produtos passaram a ser variados e a ter preços fixos, suprimindo o que acontecia em um mercado no qual os preços podem ser negociados, nele vendedores e compradores, dialogam a fim de chegar a um preço bom para ambas as partes, ou seja, essa negociação exercitava a oralidade e o trato social, desenvolvendo nos indivíduos habilidades de expressão essências para a apresentação em público.

Dentro da dinâmica capitalista, Hannah Arendt também observou que a propriedade privada, ao ser considerada sagrada, despertou uma maior necessidade de proteção, a fim de garantir o pretendido acúmulo de riqueza. À proporção que a proteção ao capital aumentou "a propriedade igualou e emulou a permanência inerente ao mundo compartilhado por todos" (ARENDT, 2007, p. 79) ${ }^{8}$, pois em uma esfera pública esvaziada Sennett $(2014)^{9}$ afirma que o espaço público adquire

4 Ver mais a respeito: SENNETT, Richard.O declínio do homem público: as tiranias da intimidade. Tradução de Lygia Araujo Watanade. Rio de Janeiro: Record, 2014, p. 450. Tradução de The fall of public man.

5 SENNETT, Richard.O declínio do homem público: as tiranias da intimidade. Tradução de Lygia Araujo Watanade. Rio de Janeiro: Record, 2014, p. 40. Tradução de The fall of public man

6 Esse processo de dissociação foi amplamente problematizado por Karl Marx em várias de suas obras, ver mais a respeito em: (Marx: 1978)

7 SENNETT, Richard.O declínio do homem público: as tiranias da intimidade. Tradução de Lygia Araujo Watanade. Rio de Janeiro: Record, 2014, p. 210. Tradução de The fall of public man

8 ARENDT, Hannah. A condição humana. Tradução de Roberto Raposo. 10. ed. Rio de Janeiro: Forense Universitária, 2007, p. 79. Tradução de The Human Condition

SENNETT, Richard.O declínio do homem público: as tiranias da intimidade. Tradução de 
movimento, ou seja, as pessoas não se apresentam para permanecer, mas apenas para passar, sem nele nada fazer ou falar, já que a sociabilidade é substituída pelo silêncio e a propriedade torna-se não o meio mas o fim em si.

Devido a esses fatores a própria concepção do que é o privado mudou, segundo Hannah Arendt o mundo privado transformou-se na esfera da intimidade que tende a ser mais valorizada com o crescimento do individualismo, ocasionando uma menor sociabilidade. Para Arendt, o retraimento para uma esfera intima padronizou as relações humanas de acordo com o modelo familiar e o domínio do que é comum passou “(...) a significar uma vida que se passa fora da vida da família" (SENNETT. 2014, p. 35) ${ }^{10}$. No âmbito familiar, as pessoas acreditam poder estabelecer vínculos seguros, sentindo-se protegidas da esfera pública, onde todos são desconhecidos. A esfera privada - entendida nesses termos - é usada para medir e interpretar o que ocorre na mundo público, não há impessoalidade desejada e vivenciada na esfera privada. Esse círculo íntimo possui o atrativo de não exigir que o ser humano seja constantemente criativo e desenvolto para se relacionar com o outro, ficando assim em uma situação cômoda, no seu mundo conhecido de experiências próximas e 'familiares'.

Esse retraimento vai além do âmbito familiar, abrange também a comunidade, porque as pessoas não se integram à sociedade, correspondente ao todo; optam por manter suas relações circunscritas a um grupo de pessoas que compartilham de características e interesses semelhantes aos seus, e por isso são capazes de expressar-se entre elas. Segundo Sennett esse “(...) sentimento de comunidade formado pelo compartilhar de impulsos tem o papel especial de reforçar o medo diante do desconhecido" (SENNETT, 2014, p. 445) ${ }^{11}$, dessa forma, pequenos grupos atomizados são formados, cujos integrantes defendem um ao outro e mostram resistência a entrada de um estranho.

Para Arendt, o não contato social bloqueia a ação, pois a execução de uma ação não ser feita isoladamente, é preciso um outro indivíduo (ARENDT, 2007) ${ }^{12}$. Apenas por meio da ação o indivíduo pode interagir em público, sem o medo de correr risco em meio a pluralidade. Somado a isso está o narcisismo contemporâneo, uma vez que o bloqueio da capacidade de ação está relacionado a incapacidade de autodistanciamento do eu. O sentimento narcisista "(...) se mobiliza nas relações sociais, e a experiência da abertura de sentimentos uns para com os outros se torna destrutiva" (SENNETT. 2014, p. 378) ${ }^{13}$. O narcisismo, na sociedade moderna, efetua uma violência silenciosa contra o indivíduo, cegando-o para seus direitos, pois é capaz de obstruir a sociabilidade humana.

Todo esse retraimento expressivo, segundo Sennett $(2014)^{14}$ fez com que o silêncio em

Lygia Araujo Watanade. Rio de Janeiro: Record, 2014, p. 30. Tradução de The fall of public man 10 SENNETT, Richard.O declínio do homem público: as tiranias da intimidade. Tradução de Lygia Araujo Watanade. Rio de Janeiro: Record, 2014, p. 35. Tradução de The fall of public man

11 SENNETT, Richard.O declínio do homem público: as tiranias da intimidade. Tradução de Lygia Araujo Watanade. Rio de Janeiro: Record, 2014, p. 445. Tradução de The fall of public man

12 ARENDT, Hannah. A condição humana. Tradução de Roberto Raposo. 10. ed. Rio de Janeiro: Forense Universitária, 2007, p. 31. Tradução de The Human Condition

13 SENNETT, Richard.O declínio do homem público: as tiranias da intimidade. Tradução de Lygia Araujo Watanade. Rio de Janeiro: Record, 2014, p. 378. Tradução de The fall of public man

14 SENNETT, Richard.O declínio do homem público: as tiranias da intimidade. Tradução de Lygia Araujo 
público se tornasse o único meio pelo qual as pessoas poderiam adentrar a esfera pública não gerando nela qualquer efeito ou transformação por estar somente corporalmente presente apenas integrando a paisagem pública. O silêncio é o sinal de morte da pretensão de se realizar o bem comum, uma vez que os indivíduos fechados em comunidades e centrados na família passam a não ver os outros como seres humanos, cujas alteridades devem ser respeitadas.

Foi uma esfera pública esvaziada que propiciou a ascensão do totalitarismo, uma forma de governo que segundo Hannah Arendt "(...) consegue erradicar do coração dos homens o amor a liberdade" (ARENDT, 1989, p. 518) ${ }^{15}$ e consequentemente a possibilidade de mover-se em um espaço, neste caso, no domínio público. O terror total associado à ideologia são ainda mais destrutivos em uma sociedade segredada em comunidades, cujos indivíduos conheceram a incivilidade no instante em que houve uma "sobrecarga de personalidade"16, derivada do eu do führer. Este por meio de uma espontaneidade controlada, associada ao processo personalização da política impõe sua dominação carismática sobre uma legião de pessoas tão distanciadas do seu próprio eu que avaliavam o caráter a julgar pela aparência e pelo discurso, pois através desses artifícios Hitler conseguiu incutir nos alemães a ideia de hegemonia da raça ariana que pregava a eliminação do estranho, do diferente que poderia contaminar a "raça pura".

Arendt afirma que "O governo totalitário [...] não poderia existir sem destruir a vida pública" (ARENDT, 1989, p. 527) ${ }^{17}$. E ele foi além, destruiu a vida privada ao colocar o indivíduo num estado de solidão, no qual há o abandono do eu por ele mesmo. O totalitarismo e qualquer governo tirânico se aproveitam do silêncio do retraimento, pois segundo Arendt $(2007)^{18}$ a violência em seu sentido mais puro atua no silêncio e por isso capaz de agir com maior eficácia naquele estado de solidão em que o ato de pensar é impossível, pois o eu não consegue mais dialogar com ele mesmo e por meio dela toda a ideia de democracia, justiça e bem comum é destruída. Destruição iniciada no momento em que a participação na vida política deixa ser o centro da ação humana, a democracia jamais se concretizará se a esfera pública estiver esvaziada.

\section{A DEMOCRACIA NA ESFERA PÚBLICA}

Nas palavras de Abraham Lincoln “(...) a democracia é o governo do povo, pelo povo e para o povo" (BONAVIDES, 2000, p. 268) ${ }^{19}$,portanto, sendo o povo, conforme Ospitali, “o conjunto de pessoas quepertencem aoEstado pela relaçãodecidadania" (BONAVIDES, 2000 apud OSPITALI, p. 31) 20, a democracia é, em síntese, a ação coletiva em prol do bem comum, sendo

\footnotetext{
Watanade. Rio de Janeiro: Record, 2014, p. 46. Tradução de The fall of public man

15 ARENDT, Hannah. Origens do totalitarismo.Tradução de Roberto Raposo. São Paulo: Companhia das Letras, 1989,p. 518. Tradução de The origins of totalitarisanim.

16 Isto Sennett entende como a imposição de sujeito que se expressa em público sobre os demais, ver mais a respeito: (SENNETT, 2014, p. 381)

17 ARENDT, Hannah. Origens do totalitarismo.Tradução de Roberto Raposo. São Paulo: Companhia das Letras, 1989,p. 527. Tradução de The origins of totalitarisanim.

18 ARENDT, Hannah. A condição humana. Tradução de Roberto Raposo. 10. ed. Rio de Janeiro: Forense Universitária, 2007, p. 35. Tradução de The Human Condition

19 BONAVIDES, Paulo. Ciência Política. 10 . ed. São Paulo: Malheiros. 2000, p. 268.

20 BONAVIDES, Paulo. Ciência Política. 10 . ed. São Paulo: Malheiros. 2000, p. 79 apud OSPITALI, Giancarlo. Istituizoni di Diritto Publicco. Padova: Cedam. 1966, p. 31.
} 
consagrado no parágrafo único do art. $1^{\circ}$ da Constituição que "todo poder emana do povo"21. Dessa forma, o retraimento para esfera privada resulta em um empecilho para a efetivação do ideal democrático, o qual pressupõe que o consenso das partes é a base e o fim último, sendo alcançado apenas pela interação na sua forma cooperativa.

O sentimento de coletividade exigido pela democracia não anula o individualismo, que apesar das conotações negativas constitui “(...) a base filosófica da democracia: uma cabeça, um voto" (BOBBIO, 1992, p. 61) 22; e nesse sentido se associa a capacidade de reflexão do indivíduo, pois ele, ao votar, realiza uma ação individual geradora de repercussão no coletivo. A visão intimista, própria de uma esfera pública esvaziada converte o referido individualismo em um demérito, visto que ele se transforma em uma barreira intransponível para aqueles que veem o íntimo como um reflexo de segurança.

Essa sensação de segurança só existe porque a partir do momento em que a pessoa se fecha em uma esfera íntima deixando de atuar em prol do coletivo, ela nega a própria existência de um problema público (SENNETT, 2014) ${ }^{23}$. A negação da existência é um pressuposto para a inatividade, nesse caso, o não agir é sinônimo de se omitir em relação aos direitos e deveres próprios de uma democracia, pois a valorização da comunidade atomizada impede a concretização do que Hannah Arendt chama de consensus iuris próprio do Estado Democrático de Direito que se relaciona com o princípio de Justiça e o reconhecimento deste pela sociedade em geral.

Há de se ressaltar também que a visão intimista impede até mesmo a compreensão da ideia de povo - elemento constitutivo de qualquer Estado - pois, a constituição de um povo pressupõe que os indivíduos se associem em torno de um interesse comum e necessário para a manutenção de todos. De fato, isso aconteceu durante a constituição do Estado, porém na modernidade a concepção de povo fragilizou-se em decorrência da atomização dos grupos humanos, passando a ser facilmente confundido com o conceito de população referente apenas ao quantitativo, pois é isso que os outros representam em uma sociedade intimista; números.

Além disso, o esvaziamento incide sobre a capacidade de representação na esfera pública, uma vez que se expor em um campo público exige a aceitação da possibilidade da frustração, porque a resolução em consenso é de longe uma das interações mais difíceis de ser concretizada. Esta frustação- em uma sociedade intimista - gera medo, já que apenas a microesfera é considerada segura, ao passo que a macroesfera e sua mutação constante representam a incerteza do desfecho. Diferentemente do que ocorria na infância. Como explicado por Sennett (2014) na teoria dos jogos infantis; a regra permite o autodistanciamento, e por serem maleáveis fazem com que mudanças e novas sensações sejam permitidas, mesmo que sejam frustradas. Nesse sentido a expressividade não é temível e a frustração não é um empecilho para a continuidade da atividade, como é no exercício da expressão pública. Além do fato de que a maleabilidade das regras permite uma inconstância conclusiva não seja necessariamente ruim, afinal permite a inclusão de novos participantes, e de 21 BRASIL. Constituição (1988). Constituição da República Federativa do Brasil. 43. ed. Brasília: Câmara dos Deputados, Edições Câmara. 2015. p. 10.

22 BOBBIO, Norbeto. A era dos direitos. 10 ed. Tradução de Carlos Nelson Coutinho. Rio de Janeiro: Elsevier, 1992, p. 61. Tradução de L'età dei Diritt.

23 SENNETT, Richard.O declínio do homem público: as tiranias da intimidade. Tradução de Lygia Araujo Watanade.

Rio de Janeiro: Record, 2014, p. 49. Tradução de The fall of public man. 
novas regras que permitam uma equalização entre os mais privilegiados e os menos privilegiados, assim como a manutenção do ideal de Justiça.

Entretanto, como o medo de frustração bloqueia a expressividade dessas comunidades atomizadas, detecta-se a difusão da personalização da política, favorecida pelos meios de comunicação eletrônica que tendem, segundo Sennett a distrair "a atenção da política para os políticos" (SENNETT, 2014, p. 397) ${ }^{24}$. Afinal, foca-se na vida privada do líder/candidato e não em suas propostas políticas. Dessa forma, o carisma passa a agir em prol da incivilidade ao impor aos outros uma personalidade, um eu que não de um alguém, pois esse alguém é visto como detentor de uma personalidade superior por fazer aquilo que os demais não fazem: expressar-se na esfera pública.

O poder do carisma em uma esfera pública esvaziada distanciada da democracia, na qual os indivíduos “(...) tratam em termos de sentimentos pessoais os assuntos públicos” (SENNETT, 2014, p. 18) ${ }^{25}$, foram determinantes para o surgimento do totalitarismo e a ascensão de Hitler. Essa nova forma de governo baseada na ideologia e no terror conduziu a solidão do indivíduo, estado no qual o próprio eu é abandonado. Tal questão é nítida na obra Eichmann em Jerusalém: um relato sobre a banalidade do mal de Hannah Arendt, pois durante o julgamento, Eichmann, acusado de cometer "crimes contra o povo judeu, crimes contra a humanidade e crimes de guerra" (ARENDT, 2007 , p. 32$)^{26}$, demonstrou a sua reduzida, quase nula, capacidade de reflexão, decorrente do abandono do eu.

Tanto no contexto totalitário quanto na sociedade atual, a personalização da política e a irreflexão conduzem a uma falsa representatividade, derivada da visão pessoal e não impessoal dos candidatos, escolhidos pelo grau de espetacularização da vida privada, que se sobrepõe as reais propostas políticas. A falsa e a falta de representatividade possuem um paralelo: o indivíduo que é falsamente representado tem a convicção que o líder o representa por crer em sua imagem carismática; enquanto os indivíduos isolados enfrentam uma crise de falta de representatividade por não serem capazes de analisar as ideias - não a imagem - de um futuro governante, que pode se desvirtuar das propostas, gerando desse modo uma falta de representação.

Dessa forma, é possível observar claramente que a sociedade mundial do século XXI encontra-se esvaziada. A exemplo disso, pode-se destacar três pontos sobre a questão dos refugiados sírios:

I) Intimismo: Existem dificuldades em emigrar para outros países por conta da alta segregação em comunidade. Esse fato impede a inserção de novos grupos no âmbito social, afinal, não há a identificação entre eles - residentes e refugiados - por conta da intimidade desenvolvida na esfera particular geradora de um sentimento de aversão ao que é estranho. Aversão reconhecida como xenofobia.

24 SENNETT, Richard.O declínio do homem público: as tiranias da intimidade. Tradução de Lygia Araujo Watanade. Rio de Janeiro: Record, 2014, p. 397. Tradução de The fall of public man.

25 SENNETT, Richard.O declínio do homem público: as tiranias da intimidade. Tradução de Lygia Araujo Watanade. Rio de Janeiro: Record, 2014, p. 18. Tradução de The fall of public man.

26 ARENDT, Hannah. Eichmann em Jerusalém: um relato sobre a banalidade do mal.Tradução de José Rubens Siqueira. São Paulo: Companhia das Letras, 1999, p. 32. Tradução de Eichmann in Jerusalem. 
II) Mutação das regras: Por mais que organizações supranacionais, como a ONU e a União Europeia, tentem por meio de mudanças nas regras conceder aos refugiados a entrada nos países, não se observa mutação referente à estabilização digna desses novos habitantes. Ou seja, a maleabilidade das normas é relativa, pois ao tentar incluir novos participantes, não garante a manutenção do ideal de Justiça representado pela Declaração Universal dos Direitos Humanos de 1948.

III) Personalização da política: Ao passo que os habitantes dos países que recebem refugiados retraem-se na microesfera, eles também tendem a eleger líderes por uma identificação pessoal demostrada pelo sentimento xenofóbico mútuo. Assim, o carisma é utilizado para convencer os eleitores de que aquele candidato é a representação viva dos ideais específicos de uma comunidade, sendo eleito única e exclusivamente por esse motivo. No entanto, isso se reflete em uma falta e falsa representatividade, pois na maioria das vezes o candidato não pode ou não pretende concretizar a promessa eleitoral - impedir a entrada dos refugiados.

\section{A CONCRETIZAÇÃO DOS DIREITOS FUNDAMENTAIS}

Sendo os direitos fundamentais a base do Estado Democrático de Direito, a interferência do esvaziamento da esfera pública atinge-os tanto quanto à democracia. Portanto, a ação coletiva que auxilia na efetivação da democracia, trabalha também a favor do reconhecimento e da positivação de tais direitos.

Apesar de esse fato ser comprovado em todas as dimensões dos direitos fundamentais, tanto na primeira quanto na segunda, é a terceira que mais o exemplifica; todas as três já foram abordadas pelo Supremo Tribunal Federal:

\footnotetext{
[...]enquanto os direitos de primeira geração (direitos civis e políticos) - que compreendem as liberdades clássicas, negativas ou formais - realçam o princípio da liberdade e os direitos de segunda geração (direitos econômicos, sociais e culturais) - que se identifica com as liberdades positivas, reais ou concretas - acentuam o princípio da igualdade, os direitos de terceira geração, que materializam poderes de titularidade coletiva atribuídos genericamente a todas as formações sociais, consagram o princípio da solidariedade e constituem um momento importante no processo de desenvolvimento, expansão e reconhecimento dos direitos humanos, caracterizados, enquanto valores fundamentais indisponíveis, pela nota de uma essencial inexauribilidade ${ }^{27}$
}

Ou seja, essa dimensão mais do que as outras, necessita de uma esfera pública fortificada para que por meio da ação comunitária os direitos passem da formalidade para a realidade. Essa passagem detalhada por Konrad Hesse naquilo que o jurista denomina de vontade de constituição demostra a necessidade de uma "consciência de que, ao contrário do que se dá com uma lei do pensamento, essa ordem não logra ser eficaz sem o concurso da vontade humana."(HESSE; MENDES, 1991, p. 04) ${ }^{28}$ Sendo assim, de nada vale a simples positivação dos direitos na Constituição 27 STF, MS 22164/SP

28 HESSE, Konrad; MENDES, Gilmar Ferreira. A força normativa da Constituição. Porto Alegre: SA Fabris 
de uma sociedade democrática, se os agentes sociais não compreenderem sua importância e não agirem em prol de efetivá-los por meio de um ato de vontade que inevitavelmente depende do coletivo.

Esse aspecto relativo à vontade de constituição, em uma esfera pública esvaziada, é posto em segundo plano em razão do senso de comunidade e da supervalorização da intimidade. Os atores sociais preocupam-se apenas ao que toca a microesfera e deixam as reflexões referentes aos interesses do coletivo nas mãos de um "governante salvador" que nada salva. Esse ato terceirizador da moral característico da falta de participação na macroesfera é o fator determinante para a não concretização dos direitos fundamentais positivados, como explica Lassalle, na constituição formal, mas não na constituição material (LASSALLE, 2001) ${ }^{29}$.

Os direitos fundamentais de terceira dimensão caracterizam-se por terem como valores centrais a solidariedade e a fraternidade, esta última diante do abandono do domínio público tem seu significado pervertido. Pois, à medida que as pessoas se fecham em comunidades o sentimento fraterno fica circunscrito àquele grupo de pessoas, as quais desenvolvem uma aversão ao que é estranho, rejeitando-o, nas palavras de Sennett “(...) é uma versão da fraternidade que leva ao fratricídio" (SENNETT, 2014, p. 383) ${ }^{30}$. Ou seja, ao se construir uma comunidade fraterna impedese a consolidação de uma "sociedade fraterna", da forma como está disposta no preâmbulo da Constituição Federal de 1988. Em relação à solidariedade, pode-se afirmar que apesar da crescente divisão do trabalho e a consequente interdependência das funções que reforçam a solidariedade orgânica, houve, ao mesmo tempo, um crescimento da solidariedade mecânica tomada aqui no sentido de que os indivíduos agrupam-se devido ao sentimento catártico, tendendo a valorizar mais a esfera familiar do que a pública.

A falta dos referidos valores reforça a segregação em comunidades e atenta contra a paz, uma vez que as comunidades estão dispostas apenas a viver e não a conviver em sociedade. Desse modo, o motivo gerador de conflitos é a diferença que não é respeitada, indo assim contra o art. $3^{\circ}$, IV, CF, que apresenta como um dos objetivos da República Federativa do Brasil "promover o bem de todos, sem preconceitos de origem, raça, sexo, cor, idade e quaisquer outras formas de discriminação" (BRASIL, 2015, p.10) ${ }^{31}$. O escopo da paz não será alcançado se as comunidades não transpuserem a microesfera, que é uma espécie de cela capaz de privar o indivíduo dar efetividade a direitos constitucionalmente garantidos.

A não construção desta "sociedade fraterna" é um óbice para a realização de todos os direitos fundamentais - especialmente os de terceira geração - prejudicando inclusive o direito que é o pressuposto dos demais: o meio ambiente. A este foi dada grande importância já em 1972 na Declaração de Estocolmo sobre o Ambiente Humano, a qual tem como princípio 1:

O homem tem direito fundamental à liberdade, à igualdade e condições de vida adequadas, em um meio ambiente de qualidade tal que lhe permita levar uma vida digna, gozar de bem-estar e Editor, p.4. 1991. Tradução de Die Normative Kraft der Verfassung.

29 LASSALLE, Ferdinand. A essência da Constituição. 6. ed. Rio de Janeiro: Lumen Juris. 2001

30 SENNETT, Richard.O declínio do homem público: as tiranias da intimidade. Tradução de Lygia Araujo Watanade. Rio de Janeiro: Record, 2014, p. 383. Tradução de The fall of public man.

31 BRASIL. Constituição (1988). Constituição da República Federativa do Brasil. 43. ed. Brasília: Câmara dos Deputados, Edições Câmara. 2015. p. 10 
é portador solene de obrigação de proteger e melhorar o meio ambiente, para as gerações presentes e futuras. ${ }^{32}$

Tal princípio está relacionado ao art. 225, CF, que apesar de estar fora do catálogo dos direitos fundamentais possui, reconhecidamente, fundamentalidade ao dispor que "todos têm direito ao meio ambiente ecologicamente equilibrado, bem de uso comum do povo e essencial à sadia qualidade de vida, impondo-se ao Poder Público e à coletividade o dever de defendêlo e preservá-lo para as presentes e as futuras gerações" (BRASIL, 2015, p. 81) 33. Como se vê expresso, é imprescindível a atuação da coletividade,cuja e inexistência dentro da esfera pública, impede o desenvolvimento da sociedade.

Além dos direitos de terceira dimensão, o constitucionalista Paulo Bonavides desenvolve a teoria da existência de direitos fundamentais de quarta geração, frutos da globalização política. Segundo o autor, "são direitos da quarta geração o direito à democracia, o direito à informação e o direito ao pluralismo" (BONAVIDES, 2004, p. 571) 34. Os reflexos do abandono do domínio público na democracia já foram apontados em tópico especifico. No tocante ao direito de informação, o crescente temor de ser impessoal anula tanto o diálogo quanto desejo de ouvir o outro, sendo assim, a circulação de informações e o debate sobre sua veracidade são dificultados. Em função disso, as mídias - de modo geral - passam a exercer uma influência indevida, algumas vezes próxima da incivilidade. Importante ressaltar que o art. $5^{\circ}, \mathrm{XIV}, \mathrm{CF}$ dispõe que "é assegurado a todos o acesso à informação [...]" (BRASIL, 2015, p. 12) ${ }^{35}$, percebe-se então o alto nível de profundidade dado ao tratamento dos direitos fundamentais na Constituição de 1988. A falta dessa disposição ao diálogo é um dos fatores que atrapalha a efetivação de meios alternativos de solução de conflitos, como mediação e conciliação.

Em relação à pluralidade, definida por Hannah Arendt como “(...) a condição da ação humana pelo fato de sermos todos os mesmos, isto é, humanos, sem que ninguém seja exatamente igual a qualquer pessoa que tenha existido, exista ou venha a existir" (ARENDT, 2007, p. 16) ${ }^{36}$, verfica-se à dificuldade de sua manifestação na esfera pública Pois, devido à inexistência da ação no espaço público, pelo fato desta necessitar de outros seres humanos, a ideia de pluralidade tornase algo utópico assim como a existência de um direito a pluralidade. Nesse sentido, novamente, têm-se um afrontamento ao desejo da Assembleia Nacional Constituinte, expresso no preâmbulo de construir uma "sociedade fraterna, pluralista e sem preconceitos" (BRASIL, 2015, p. 10) ${ }^{37}$.

Estreitamente relacionado ao tema do presente artigo está o direito fundamental previsto no art. $5^{\circ}, \mathrm{X}, \mathrm{CF}$, segundo o qual "são invioláveis a intimidade, a vida privada, a honra e a imagem

\footnotetext{
32 DECLARAÇÃO DE ESTOCOLMO SOBRE O AMBIENTE HUMANO. A Conferência das Nações Unidas em Estocolmo. 5 a 16 jun. 1972. Disponível em: <http://www.silex.com.br/leis/normas/estocolmo.htm>. Acesso em: 18 out. 2017.

33 BRASIL. Constituição (1988). Constituição da República Federativa do Brasil. 43. ed. Brasília: Câmara dos Deputados, Edições Câmara. 2015. p. 81.

34 BONAVIDES, Paulo. Curso de Direito Constitucional. 15. ed. São Paulo: Malheiros. 2004. p. 571.

35 BRASIL. 2015, p. 12.BRASIL. Constituição (1988). Constituição da República Federativa do Brasil. 43. ed. Brasília: Câmara dos Deputados, Edições Câmara. 2015. p. 10

36 ARENDT, Hannah. A condição humana. Tradução de Roberto Raposo. 10. ed. Rio de Janeiro: Forense Universitária, 2007, p. 16. Tradução de The Human Condition

37 BRASIL. Constituição (1988). Constituição da República Federativa do Brasil. 43. ed. Brasília: Câmara dos Deputados, Edições Câmara. 2015. p. 10
} 
das pessoas, assegurado o direito a indenização pelo dano material ou moral decorrente de sua violação" (BRASIL, 2015, p. 11) ${ }^{38}$. A Constituição adotou uma diferenciação entre vida privada e intimidade, no entanto a doutrina ainda é divergente; algumas abordagens tratam ambos como conceitos uniformes, outras preferem a diferenciação em razão de estar em maior conformidade com o texto constitucional. Nesse sentido Tércio Sampaio Ferraz Júnior diz que:

A intimidade é o âmbito do exclusivo que alguém reserva para si, sem nenhuma repercussão social, nem mesmo ao alcance de sua vida privada que, por mais isolada que seja, é sempre um viver entre os outros (na família, no trabalho, no lazer em comum). [...] Já a vida privada envolve a proteção de formas exclusivas de convivência. Trata-se de situações em que a comunicação é inevitável (em termos de alguém com alguém que, entre si, trocam mensagens), das quais, em princípio, são excluídos terceiros. (FERRAZ JÚNIOR, 1992) ${ }^{39}$

O que ocorre na modernidade é a celebração expansiva da intimidade, não ponderada em relação aos demais direitos fundamentais, que encontram no excesso dela uma barreira para a concretização desses direitos. Defender a intimidade e a vida privada é necessário, pois nelas estão contidos aspectos da personalidade e identidade das pessoas que não podem ser violados, no entanto o erro está não em defender, mas em fazer do direito fundamental a intimidade, o centro do agir.

Depreende-se de todos esses empecilhos expostos, que tanto a eficácia quanto a elaboração de direitos fundamentais é prejudicada, pois os direitos que estão constitucionalizados não alcançam a devida validade social dentro de uma esfera pública esvaziada. Além de que, a proteção desses direitos no âmbito universal “(...) depende da própria natureza da comunidade internacional, ou, mais precisamente, do tipo de relações existentes entre os Estados singulares, e entre cada um

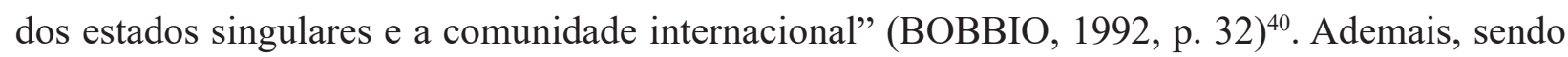
eles direitos que têm por característica a historicidade, “(...) nascem em certas circunstâncias, caraterizadas por lutas em defesa de novas liberdades contra velhos poderes, e nascidos de modo gradual, não todos de uma só vez e nem todos de uma vez por todas" (BOBBIO, 1992, p. $05)^{41}$, devido à falta de interação e desejo de transformação coletiva da realidade a instituição de novos direitos fundamentais fica comprometida, uma vez que sequer aos já conquistados é dada efetividade.

Tal falta de efetividade provem não somente da falta de vontade de constituição dos indivíduos, mas também do fato de que a não interação social e a carência de debate sobre a importância e a necessidade dos direitos fundamentais prejudica- se a possível ponderação entre esses direitos quando há colisão. Pois, é difícil determinar qual direito é mais importante quando

38 BRASIL. Constituição (1988). Constituição da República Federativa do Brasil. 43. ed. Brasília: Câmara dos Deputados, Edições Câmara. 2015. p. 11

39 FERRAZ JÚNIOR, Tércio Sampaio. Sigilo de dados: o direito à privacidade e os limites à função fiscalizadora do Estado. Revista dos Tribunais, Cadernos de Direito Constitucional e Ciência Política. São Paulo, ano 1, p. 77-90, 1992.

40 BOBBIO, Norbeto. A era dos direitos. 10 ed. Tradução de Carlos Nelson Coutinho. Rio de Janeiro: Elsevier, 1992, p. 37. Tradução de L'età dei Diritt

41 BOBBIO, Norbeto. A era dos direitos. 10 ed. Tradução de Carlos Nelson Coutinho. Rio de Janeiro: Elsevier, 1992, p. 05. Tradução de L'età dei Diritt 
há situações conflitantes entre comunidade e sociedade. Ou seja, devido à ausência de diálogos não se forma uma cosmovisão do que seja ou representede fato uma sociedade, e a visão intimista não permite a satisfação parcial do eu - independentemente dos efeitos que isso trará para outremlevando à crença de que o debate para a ponderação é desnecessário já que não conduzirá a completa satisfação de uma ou outra parte envolvida. Essa postura vai na contramão do que se entende por exercício da cidadania, base do Estado Democrático de Direito.

\section{OS EFEITOS DO ABANDONO DO DOMÍNIO PÚBLICO NA CIDADANIA}

A cidadania pode ser representada como a pertença passiva e ativa de indivíduos em um Estado - nação com certos direitos e obrigações universais em um específico nível de igualdade. Portanto, torna-se visível que a omissão por parte da população referente ao que interessa o domínio público, faz com que essas pessoas deixem de ser denominadas cidadãs. A cidadania está intimamente ligada às ações dos indivíduos a respeito dos seus direitos e deveres (como explícito no art. $1^{\circ}$ do atual Código Civil). Consequentemente, se as pessoas não atuam de tal forma, não há cidadania. Além disso, os direitos não se efetivam, visto que dependem da vontade humana de concretização e medidas públicas de implementação.

De que vale uma democracia restringida a um mero enunciado na Constituição que determina que "todo poder emana do povo" se esse povo não utiliza a cidadania ativa para exercer esse poder a si conferido? Nas palavras de Sérgio Alves Gomes, um dos empecilhos para a concretização do ideal democrático é a falta de vontade política para os atos de interesse coletivo, da mesma forma que a vontade arbitrária do não-agir segundo os interesses da coletividade (GOMES, 2002, 13) ${ }^{42}$. Ou seja, a falta de cidadãos.

Dessa forma, chega-se ao ápice dessa análise: posto que o esvaziamento da esfera pública tem como efeito inicial a degradação da cidadania; a falta de cidadãos é o que ocasiona um efeito de trasbordamento nas adversidades causadas em decorrência deste esvaziamento. Da supressão da cidadania tem-se a deturpação dos direitos fundamentais e por consequência a inexistência da democracia. A visão do Estado como um fim e não como instrumento corroborador da realização

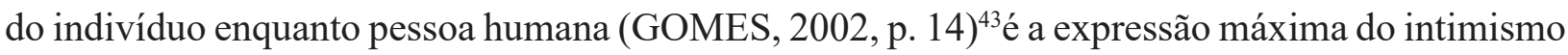
e por consequência a ruína não só do Estado como também da sociedade pautada sobre ele.

Ao mesmo passo que a degradação iniciou-se concepção restrita da cidadania, a reconstituição também pode ocorrer a partir de uma concepção ampla e inclusiva. A reconciliação entre microesfera e macroesfera através do reconhecimento de direitos e deveres para com a coletividade pode gerar um efeito reestruturador que venha a desfazer os malefícios do isolamento na esfera particular, podendo inclusive ser responsável pela realocação das pessoas no meio comunal. Seja por meio da cidadania passiva, seja pela ativa, a preocupação com algo que vá além do círculo pessoal de cada um já é um passo em direção a reconstrução da efetividade e eficácia

42 GOMES, Sérgio Alves. Hermenêutica Jurídica e Constituição do Estado Democrático de Direito. 2.ed. Rio de Janeiro: Forense, 2002, p.13

43 GOMES, Sérgio Alves. Hermenêutica Jurídica e Constituição do Estado Democrático de Direito. 2.ed. Rio de Janeiro: Forense, 2002, p.14. 
dos direitos fundamentais e dos ideais democráticos postos na Constituição.

Esse caminho inverso deve ser percorrido para que as contradições entre constituição material e formal sejam revistas. Essa revisão será a confirmação da Constituição que foi denominada cidadã por meio de um povo que assim também o será. O povo cidadão, dotado do poder garantido a ele pela norma constitucional, representa a proteção máxima, necessária e essencial que todo ordenamento jurídico deve ter.

\section{CONCLUSÃO}

Com base no exposto depreende-se que a esfera pública esvaziada, resultante da alienação dos atores sociais aos interesses comunitários, impede a manifestação da democracia, dos direitos fundamentais e da cidadania. Dessa forma, verifica-se como solução a ação coletiva baseada em políticas públicas de implementação provenientes do dialogo intersubjetivo.

Essa solução assemelha-se aquilo que Habermas denomina de Ética do discurso, na qual todas as pessoas afetadas devem participar do debate. Com isso o diálogo é a fonte do consenso, expressão da vontade racional, explicitada pelo melhor argumento. Os indivíduos são introduzidos na vida pública por meio da linguagem e da inexistência do medo da frustração, partindo do objetivo de que a busca pela justiça e pelo bem comum há de se concretizar com as políticas públicas de implementação desses ideais e que a moral não seja terceirizada como era no regime totalitário.

No entanto, deve-se ter em mente que a comunicação na macroesfera esvaziada limitase ao círculo comunal não transpondo o agir comunicativo para a sociedade. Assim não se pode pressupor que as pessoas sempre estarão abertas ao diálogo, sobretudo quando este referir-se a aspectos que fogem a fronteira da comunidade.

Há de se destacar ainda o aspecto histórico dos direitos fundamentais, os quais dependem inevitavelmente da ação social tanto para sua elaboração quanto para sua efetivação. Pois, a partir do instante que se anula a ação dialógica impede--se o surgimento de novas situações e necessidades entre os agentes, desse modo a fundamentalidade bem como a proteção de novos ou de direitos já existentes fica marginalizada.

Fica claro, portanto, que o abandono do domínio públicojuntamente com o desenvolvimento anormal de uma sociedade intimista gera uma gama de dificuldades que afetam os ramos públicos cruciais para a vida humana. Afinal afeta os direitos basilares do Estado Democrático de Direito, assim como a convivência social em forma de cidadania. Essa decadência da esfera pública é ao mesmo tempo a decadência da sociabilidade e só pode ser solucionada unicamente, mas não simplesmente, pelo agir comunicativo. 


\section{REFERÊNCIAS}

ARENDT, Hannah. Origens do totalitarismo. Tradução de Roberto Raposo. São Paulo: Companhia das Letras, 1989.

ARENDT, Hannah. Eichmann em Jerusalém: um relato sobre a banalidade do mal. Tradução de José Rubens Siqueira. São Paulo: Companhia das Letras, 1999.

ARENDT, Hannah. A condição humana. Rio de Janeiro: Forense Universitária, 2005

BONAVIDES, Paulo. Ciência Política. 10 ed. São Paulo: Malheiros. 2000.

BONAVIDES, Paulo. Curso de Direito Constitucional. 15. ed. São Paulo: Malheiros. 2004.

BOBBIO, Norberto. A era dos direitos. Tradução de Carlos Nelson Coutinho. Rio de Janeiro: Elsevier, 1992.

BRASIL. Constituição (1988). Constituição da República Federativa do Brasil. 43. ed. Brasília: Câmara dos Deputados, Edições Câmara. 2015.

DATAFOLHA. Apoio à democracia recua. Instituto De Pesquisas Datafolha. Opinião Pública. São Paulo, out. de 2017 Disponível em: $<\underline{\text { http://datafolha.folha.uol.com.br/ }}$ opiniaopublica/2017/10/1923930-apoio-a-democracia-recua.shtml $>$ Acesso em: 09. Out .2017.

DECLARAÇÃO DE ESTOCOLMO SOBRE O AMBIENTE HUMANO. A Conferência das Nações Unidas em Estocolmo. 5 a 16 jun. 1972. Disponível em: <http://www.silex.com.br/leis/ normas/estocolmo.htm>. Acesso em: 18 out. 2017.

FERRAZ JÚNIOR, Tércio Sampaio. Sigilo de dados: o direito à privacidade e os limites à função fiscalizadora do Estado. Revista dos Tribunais, Cadernos de Direito Constitucional e Ciência Política. São Paulo, ano 1, 1992.

GOMES, Sérgio Alves. Hermenêutica Jurídica e constituição do Estado Democrático de Direito. Rio de Janeiro: Forense, 2002.

HESSE, Konrad; MENDES, Gilmar Ferreira. A força normativa da Constituição. Porto Alegre: SA Fabris Editor, 1991.

LASSALLE, Ferdinand. A essência da Constituição. 6. ed. Rio de Janeiro: Lumen Juris. 2001.

MARX, Karl, ENGELS, Friedrich. Manifesto do Partido Comunista. Rio de Janeiro: Zahar Editores, 1978.

SARLET, Ingo Wolfgang. A eficácia dos direitos fundamentais. 2. ed. Porto Alegre: Livraria do Advogado, 2001.

SENNETT, Richard. O declínio do homem público: as tiranias da intimidade. Tradução de Lygia Araujo Watanade. Rio de Janeiro: Record, 2014. 
Como citar: RIBEIRO, Luci, SOUZA, Hellen Luana de. ROCHA, Daniela Lucca. Os efeitos da decadência na esfera pública. Revista do Instituto de Direito Constitucional e Cidadania, Londrina, v. 3, n. 1, p. 155-170, jan/jun. 2018.

Recebido em: 23/03/2018

Aprovado em: 20/04/2018 